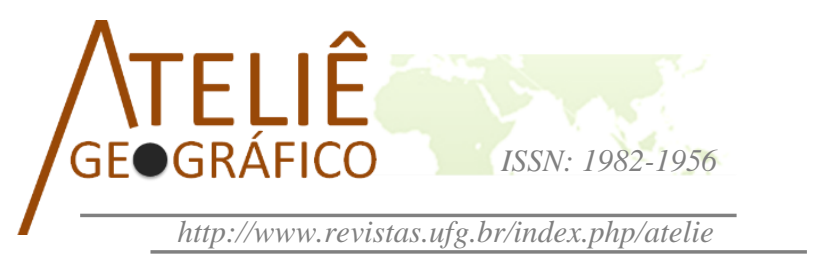

\title{
Os micropolos geográficos de ligação do estado de Mato Grosso do Sul e suas articulações territoriais: um estudo dos municípios fronteiriços de Ponta Porã e Corumbá
}

\author{
Los micropolos geográficos de conexión de la província de \\ Mato Grosso do Sul y sus articulaciones territoriales: um \\ estúdio de los municípios fronterizos de Ponta Porã y \\ Corumbá
}

\section{Geographic connection micropolis of the state of Mato Grosso do Sul and their territorial links: a study of the frontier counties of Ponta Porã and Corumbá}

Walter Guedes da Silva

Mestrado em Estudos Fronteiriços do Campus do Pantanal da

Universidade Federal de Mato Grosso do Sul

E-mail: guedes@uems.br

\begin{abstract}
Resumo
O objetivo deste artigo é fazer um estudo da geografia urbana regional, no estado de Mato Grosso do Sul - Brasil, tendo como base os micropolos geográficos de ligação, representados pelas cidades de Corumbá, fronteira com a Bolívia, e, de Ponta Porã, fronteira com o Paraguai. Essas cidades apresentam uma condição distinta de cidades de fronteira, que lhes confere uma dinâmica interna e externa de fluxo de pessoas, serviços e capital, característica de suas posições geográficas. Enquanto procedimento metodológico, adotou-se as orientações do trabalho de Oliveira \& Martins Jr. (2016) que estabelece uma base metodológica para definição das articulações regionais, nacionais e internacionais dos municípios, pautada em três indicadores, de acordo com suas características: 1) capacidade de autogestão; 2) capacidade de sustentação da base territorial e, por fim, 3) capacidade de articulação regional, nacional e internacional. Essas cidades apresentam uma condição distinta de cidades fronteiriças, dando-lhes uma dinâmica interna e externa de fluxo de pessoas, serviços e capital característica de suas posições geográficas.
\end{abstract}

Palavras-chaves: Regionalização; Fronteira; Indicadores. 


\begin{abstract}
Resumen
El objetivo de este artículo es hacer un estudio de la geografía urbana regional, en la provincia de Mato Grosso do Sul - Brasil, teniendo como base los micropolos geográficos de conexión, representados por las ciudades de Corumbá, frontera con Bolivia, y, de Ponta Porã, frontera con Paraguay. Esas ciudades presentan una condición distinta de ciudades de frontera, conferiéndoles una dinámica interna y externa de flujo de personas, servicios y capital, característica de sus posiciones geográficas. Como aporte metodológico, se ha adoptado las orientaciones del trabajo de Oliveira \& Martins Jr. (2016) que establece una base metodológica para tres indicadores, en conformidad con sus características: 1) capacidad de autogestión; 2) capacidad de sustentación de la base territorial y, por fin, 3) capacidad de articulación regional, nacional e internacional. Estas ciudades presentan una condición distinta de las ciudades fronterizas, dándoles una dinámica interna y externa de flujo de personas, servicios y capital característicos de sus posiciones geográficas.
\end{abstract}

Palabras-clave: Regionalización; Frontera; Indicadores.

\begin{abstract}
The aim of this article is to make a study of urban geography regional in the state of Mato Grosso do Sul - Brazil, based on the geographic connection micropolis, represented by the cities of Corumbá, border with Bolivia; and Ponta Porã, border with Paraguay. These cities present a distinct condition of frontier cities, giving them an internal and external dynamic of flow of people, services and capital characteristic of their geographical positions. As a methodological procedure, the guidelines of Oliveira \& Martins Jr. (2016) was adopted, which establishes a methodological basis for defining the regional, national and international articulations of counties, listed on three indicators according to their characteristics: 1) capacity of self-management; 2) capacity to sustain the territorial base and; 3) regional, national and international articulation capacity. These cities present a distinct condition of frontier cities, giving them an internal and external dynamic of flow of people, services and capital characteristic of their geographical positions.
\end{abstract}

Keywords: Regionalization; Frontier; Indicators.

\title{
Introdução
}

A dinâmica de um mundo com ampliação da divisão internacional do trabalho e com aumento nas trocas de bens, pessoas, serviços e informações contribui para mudanças na forma e no conteúdo em escala local e/ou regional, conferindo-lhes maior nível de complexidade e, consequentemente, um maior esforço para sua compreensão.

No Brasil, os estudos regionais adquiriram maior importância a partir da criação do Instituto Brasileiro de Geografia (IBGE) em 1937, quando os processos de regionalização do país se institucionalizaram com o objetivo de promover estudos e políticas voltados ao crescimento econômico, estando fortemente ligados ao planejamento e às políticas administrativas do poder público em suas diversas escalas de organização. 
As mudanças que recaem sobre o território e sua organização, diante do mundo globalizado, revelam a necessidade de repensar, metodologicamente, a região. É preciso superar a falsa ideia de que a região se dissolve diante de uma possível homogeneização promovida pela globalização. Autores como Lencioni (2004), Haesbaert (2014), Santos (2008) e Corrêa (2007) contribuem para a valorização teórica e metodológica dessa categoria e para as possibilidades de sua empiricização no mundo contemporâneo.

Os processos de conformação regional, favorecidos por características endógenas que propiciam as interações e ligações territoriais e, por conseguinte, o dinamismo do desenvolvimento local, podem ser melhor observados em áreas distantes de grandes centros econômicos e com baixa densidade demográfica, como é o caso do estado de Mato Grosso do Sul - Brasil, composto por 78 municípios em que apenas a capital Campo Grande possui uma população superior a 500 mil habitantes. Entre os demais municípios, somente Dourados (196.035 hab.), Corumbá (103.703 hab.) e Três Lagoas (101.791 hab.) são de porte médio, situados em uma faixa entre 100 e 500 mil habitantes; 21 municípios com população entre 20 a 100 mil habitantes e uma ampla maioria, 53 municípios, com menos de 20 mil habitantes (IBGE, 2010).

Essa espacialização, com predomínio de municípios com baixa densidade demográfica, demonstra que cidades de menor porte, que não se destacam como polo de ligação na rede urbana, podem ser responsáveis pela constituição de novos arranjos e articulações territoriais que as colocam como um polo de menor grandeza na rede urbana estadual, que denominamos de micropolo geográfico de ligação. Analisar a dinâmica local e regional em que esses micropolos estão inseridos é fundamental para a compreensão da própria dinâmica da economia regional do estado de Mato Grosso do Sul.

Em diversas escalas, as regionalizações buscam privilegiar as áreas mais dinamizadas e inseridas em uma integração competitiva do mundo globalizado, naquela velha concepção de polos capazes de irradiar o desenvolvimento para os espaços circundantes. Entretanto, para regiões nas quais a estruturação da rede urbana parece, ainda, em construção, é fundamental compreender a existência de processos endógenos que levam a articulação regional e que não está diretamente relacionada às regionalizações oficialmente estabelecidas.

Dessa perspectiva, o objetivo deste artigo é fazer um estudo da geografia urbana regional no estado de Mato Grosso do Sul - Brasil, tendo como referência a localização dos micropolos geográficos de ligação, representados, nesta pesquisa, pelas cidades de Corumbá, fronteira com a Bolívia; e Ponta Porã, fronteira com o Paraguai.

Além da Introdução, este trabalho está estruturado em quatro partes. Na revisão bibliográfica apresentamos uma discussão da Região enquanto categoria de análise geográfica e do processo de regionalização. Na segunda parte, discutimos os procedimentos metodológicos utilizados para identificação do micropolo geográfico de ligação e de sua abrangência local, nacional e internacional. Em seguida, realizamos um 
estudo de caso sobre as regiões fronteiriças de Ponta Porã e Corumbá. Por fím, apresentamos uma discussão sobre as principais considerações finais da pesquisa.

\section{Região e Regionalização}

Definir um recorte geográfico e chamá-lo de região é, antes de tudo, o reconhecimento de uma configuração geográfica que se define pelo entendimento das relações internas e externa que se processam em um determinado subespaço. Assim, toda regionalização é, no dizer de Haesbaert (2014, p. 23), um ato de poder, "o poder de recortar, de classificar e, muitas vezes, também de nomear."

Ao longo da história é possível observar que a ciência utilizou-se de diferentes concepções teórico-filosóficas para definir o que é região e como se daria o processo de regionalização. No entanto, utilizar, nos dias atuais, a categoria região como recorte espacial capaz de elucidar a complexidade das relações, exige uma atualização do conceito dessa categoria compreendendo que a mesma deve ser vista "como um espaçomomento cuja diferenciação resulta muito mais da efetiva articulação espacial em rede, complexa, amplamente aberta à transformação, cuja dominância [...] dependerá dos grupos sociais e do contexto geo-histórico em que estiver inserida." (HAESBAERT, 2014, p. 196).

A região não deve ser entendida como um espaço homogêneo, dentro da região é possível que haja uma fragmentação dos espaços, quebrando a aparente característica de continuidade espacial dessa região. Analisando o caráter descontínuo de uma região, Allen; Massey \& Cochrane (1998) incluem dois importantes elementos na análise regional como representações e identidades. Nessa perspectiva, os autores trazem uma nova abordagem que se contrapõe à tradicional visão de continuidade espacial da região, ao defenderem que "as regiões são construídas tanto material quanto discursivamente, dentro de um sistema de representações.” (HAESBAERT, 2014, p. 83).

Uma das principais contribuições da proposta de Allen; Massey \& Cochrane (1998) está no fato de os mesmos terem destacado o caráter fragmentado interno às regiões, que constituem os “buracos" - uma descontinuidade de "áreas 'dentro' da região que não se caracterizam pelos mecanismos/aspectos que fazem parte dos critérios da definição regional.” (ALLEN; MASSEY; COCHRANE, 1998, p. 55).

Dessa forma, uma região pode apresentar um caráter descontínuo dos fenômenos territoriais, pois o que dá sentido a uma região é a unidade interna que a constitui enquanto totalidade. De acordo com Lencioni (2015, p. 10): "É importante observar que essa unidade e integração não é definida pela continuidade de elementos espaciais, nem pela homogeneidade de fenômenos, mas pela integração que apresenta."

A ideia defendida por Scott (2001) vai ao encontro da concepção de região polarizada que privilegia a Cidade. Para o autor, a análise da região é centralizada na análise da Cidade - uma proposição de Cidade-região, entendendo que a forma pela qual essa Cidade-região se articula e se integra com os territórios, seria via redes 
estruturais econômicas. Na visão de Scott (2001, p. 11), as cidades-região "funcionam, cada vez mais, como nós espaciais essenciais da economia global."

Por serem cidades que apresentam maior capilaridade regional, com maior circulação de produtos e concentração de serviços, essas cidades acabam atraindo o interesse do capital por sua melhor condição de integração com as economias nacional e internacional. Segundo Arraias (2008, p. 88), “o conceito de cidade-região apresenta como mérito a lembrança que devemos fomentar a discussão política em espaços integrados por uma rede urbana densa e marcados por desafios institucionais comuns."

A abordagem da região proposta tanto por Allen; Massey \& Cochrane (1998) como por Scott (2001), privilegiam o caráter mesoescalar em uma relação com a dinâmica global. Nessa visão, o Estado não desaparece de cena completamente, mas perde espaço de atuação da gestão de mercado da economia regional.

Assim, a região não estaria subordinada apenas a escala Global, ela seria fruto de uma relação com múltiplas escalas. Lencioni (2004, p. 27), ao tratar especificamente de "escala" como representação e compreensão da realidade regional, afirma que "o conceito de região está vinculado à ideia de parte de um todo", em que cada parte é, ao mesmo tempo, parte do todo e totalidade em si. Enquanto parte de um todo, a escala ganha relevância para o recorte regional que não deve ser entendida como uma relação aritmética de representação, daí a importância dos mapas, pois "são eles que realizam a escala, quer como proporção, quer como representação de conteúdos.” (LENCIONI, 2003, p. 29).

Vejamos agora como essa discussão de região é feita dentro da ótica da Central Place Theory (Teoria dos Lugares Centrais). Considerado como o precursor da discussão de rede de Cidades no pensamento regional, está Walter Christaller (1966) com a obra Central Places in Southern German. Segundo Bradford \& Kent (1977) a Teoria dos Lugares Centrais de Christaller, que tem como pressupostos básicos o raio de atuação de um bem e serviço, busca explicar a organização espacial das povoações e das áreas de influência. Essa concepção de Cidade-região se assemelha, em alguns aspectos, a Teoria dos Polos de Desenvolvimento de François Perroux, que foi quem desenvolveu a ideia de polarização de um lugar central.

Ao discutirem a contribuição da Teoria dos Lugares Centrais de Christaller, Getis \& Getis (1966, p. 87) afirmam que existem localidades que são centros de regiões denominados "lugares centrais", existindo também os lugares não centrais denominados "lugares dispersos". Ao falar especificamente dos lugares centrais, Christaller destaca que existem níveis de importância diferenciados, "suas funções centrais se estendem por regiões em que existem outros lugares centrais de menor importância."

Nesse sentido, uma região se constitui como uma área ao redor de um lugar central, influenciada pelo alcance de um bem que tem seu alcance próprio, sendo diferente para cada lugar central e para cada momento histórico. Assim, o recorte regional não se daria por mera proximidade, mas por conexões espaciais que podem ser alteradas com o tempo, levando a um novo recorte regional. 
A Teoria dos Lugares Centrais desenvolvida por Christaller revela, portanto, a existência de uma hierarquia urbana formada por centros urbanos com tamanho e oferta de serviços distintos, levando Garcia \& Lemos (2006, p. 3) a afirmarem que essas ideias sugerem uma visão de "área de mercado" a ser polarizada por um centro urbano concentrador de população e serviços, onde "o nível de terciarização de uma localidade é o melhor indicador de sua capacidade de polarização."

Diferente da concepção de região homogênea, que divide o espaço com níveis hierárquicos e diferenciação espacial na busca de características homogêneas, na região funcional da Teoria dos Lugares Centrais o espaço é visto com diferenças internas e com uma estruturação de múltiplas relações capazes de dar forma e sentido a um subespaço. Assim, a Cidade ganha maior relevância na dinâmica regional, pois é ela que organiza sua hinterlândia e os demais centros urbanos de menor porte. (GOMES, 2001).

Nessa perspectiva, Gomes (2001, p. 64) chama a atenção para a "valorização da vida econômica como fundamento destas trocas e deste fluxo, sejam eles de mercadorias, de serviços, de mão-de-obra", que ocorre ao se analisar os fluxos e as trocas que se organizam na região funcional.

De acordo com Santos (2008, p. 88) a região não deve ser entendida como uma "solidariedade orgânica", mas sim, como "solidariedades organizacionais" que, diferente das regiões do passado, são regidas por nexos de informação. Essas regiões são subespaços com recortes tanto horizontais, como as áreas produtivas que são "a fábrica da produção propriamente dita"; quanto verticais, como os sistemas urbanos que "dão conta sobretudo dos outros momentos de produção (circulação, distribuição e consumo)."

Na visão de Santos \& Silveira (2006, p. 21), o espaço não é somente visto, ele também é hierarquizado, "a divisão territorial do trabalho cria uma hierarquia entre lugares e redefine, a cada momento, a capacidade de agir das pessoas, das firmas e das instituições."

Assim, o nível de polarização de uma cidade está diretamente relacionado com o grau de articulações estabelecidas por essa localidade com os demais centros urbanos, ou seja, quanto maior for a dinâmica do setor terciário, representado pelas trocas de bens e serviços de uma localidade urbana a outra, maior será sua expressão na rede urbana.

O estudo Regiões de Influência das Cidades (REGIC) de 2008, é uma publicação do IBGE que teve como objetivo definir a hierarquia dos centros urbanos e delimitar as regiões de influência das cidades. Para isso, classificou as cidades em cinco grandes níveis que são subdivididos em outros subníveis: Metrópoles - 12 principais centros urbanos do País; Capital regional - 70 centros que se relacionam com o estrato superior da rede urbana; Centro sub-regional - 169 centros com atividades de gestão menos complexas; Centro de zona - 556 cidades de menor porte, com atuação restrita à sua área mais próxima; Centro local -4.473 cidades cuja centralidade e atuação não extrapolam os limites do seu município. Por essa classificação, as Cidades de Ponta Porã 
e Corumbá foram consideradas como Centros de Zona A, um nível intermediário de cidades de pequeno porte com baixo poder de influência nos municípios próximos.

Vale destacar que ao discutir os diferentes papéis e posições que as cidades assumem na rede urbana, que comumente são diferenciados por níveis hierárquicos, Santos (2005, p. 137) afirma que esses níveis "são coisas agradáveis de olhar, sem dúvida instrumentos de aproximação da realidade, mas não suficientes para sua interpretação." À medida que a cidade passa a ter uma relação mais direta com a demanda da sua região, e à proporção que cada região se especializa, "a cidade se dobra a essa demanda, reforma-se, reorganiza-se, refaz-se, recria-se.”

\section{Proposição Metodológica}

Os caminhos teórico-metodológicos de recorte regional têm privilegiado aqueles territórios mais dinamizados e centralizadores de serviços e capital. Territóriosrede, rede regional e cidade-região, são mais claramente vislumbrados no contexto das regiões metropolitanas já consolidadas. Dessa forma, é necessário repensar o local e a região e suas articulações para além de seu marco institucional, tendo em vista que os processos que envolvem essas articulações e as interações urbano-regional não se criam, se consolidam pelas dinâmicas e articulações promovidas por relações horizontais que propiciam condições de complementaridade e cooperação.

Para além dos grandes centros econômicos, uma leitura a partir do micropolo geográfico de ligação permite compreender a complexidade das interações presentes em áreas que não possuem expressiva visibilidade em escala nacional e que não se destacam como um polo que está relacionado ao cruzamento entre os centros geradores de cargas com os centros geradores de viagens, mas possuem destaque em nível local. Trata-se de uma interpretação de sistemas urbano-regionais que podem se conformar como regiões, a partir das inter-relações que estabelecem em termos da intensidade e qualidade da circulação e do fluxo de pessoas, mercadorias, serviços e capital, em escala local.

O crescimento nas relações horizontais - muitas vezes fruto da própria especialização dos centros urbanos de menor porte, bem como da proximidade geográfica - contribui para uma hierarquização de nível intermediário capaz de reconfigurar o território regional. Assim, Cidades de menor porte populacional podem gerar centralidade regional ao desempenharem importante papel na circulação de mercadorias e pessoas. Essas localidades podem movimentar grandes quantidades de produtos, mas não, necessariamente, um grande movimento de viagens e vice versa.

Segundo Oliveira (2016), a possibilidade de uma localidade gerar movimento de cargas e a mobilidade de pessoas em uma cidade, tende a estar relacionada com as atividades econômicas específicas dessa localidade. No entanto, não é uma regra, pois uma Cidade, por exemplo, em que a atividade econômica principal é a extração de minério de ferro e manganês pode gerar grande quantidade de cargas, mas não gera, na mesma proporção, grande mobilidade de pessoas. 
Nesse contexto, identificar a capacidade desses micropolos é importante para mostrar sua função integradora; detectar a capacidade da cidade em atrair serviços; identificar as condições e valorizações do uso do solo; identificar as diversas formas de acessibilidade; abalizar as condições de localização e seus impactos relacionados; assinalar os diversos graus de investimentos realizados ou de possibilidades de viabilização; sinalizar as vantagens comparativas; vislumbrar os possíveis níveis de inovação; e identificar sua área de influência e suas redes de ligações externas. (OLIVEIRA, 2016).

O micropolo propicia a construção de uma centralidade urbano-regional para uma cidade principal, entretanto, a definição seria dada por elementos concretos, o que exige um esforço na busca de indicadores capazes de dar elementos à compreensão da morfodinâmica social e econômica do território Sul-Mato-Grossense.

Neste estudo nos baseamos em Oliveira \& Martins Jr. (2016) que apresentam três indicadores responsáveis pela classificação dos municípios de acordo com suas características: 1) Capacidade de autogestão; 2) Capacidade de sustentação da base territorial e; 3) Capacidade de articulação regional, nacional e internacional. Com base na produção desses indicadores, detalhados abaixo, foi possível uma análise comparativa desses municípios com outros do estado de Mato Grosso do Sul e com as demais unidades federativas do Brasil.

Para identificar o indicador da capacidade de autogestão dos municípios, foram observadas as evoluções das receitas e despesas públicas dos municípios em um período de três anos (2013-2015), consolidando indicadores fiscais apropriados a uma resposta sobre o nível de gestão dos municípios, no caso:

a. Capacidade de geração de receitas próprias do município para verificar o grau de autonomia de suas receitas (receita tributária / receita corrente).

b. Dependência do município em relação a outras autarquias (fundo partidário dos municípios / receita corrente X 100).

c. Dependência dos municípios em relação ao repasse do Imposto sobre Circulação de Mercadoria e Serviço (Repasse do ICMS / receita corrente X 100).

d. Grau de interferência dos gastos sociais em relação às receitas (despesas com saúde + educação + assistência social X 100).

e. Grau de interferência dos gastos com pessoal e as receitas (pessoal, encargos, sentenças judiciais, entre outras / despesa correntes).

f. Parcela dos investimentos nos orçamentos municipais (investimentos / receita corrente).

Segundo Oliveira \& Martins Jr. (2016, p. 244-245), a obtenção desse indicador é fundamental para a análise da capacidade de autogestão do município, "e, a partir de todos os dados é possível depreender sobre qual aspecto da administração municipal é 
mais estável e, consequentemente, qual parte está mais comprometida com possíveis desarranjos."

Essa metodologia de conjunto de índices já é utilizada pelo sistema Firjan de desenvolvimento municipal, que os contabiliza como forma de visualizar a realidade dos municípios brasileiros e sua capacidade de promover o desenvolvimento.

Já para o indicador da capacidade de sustentação territorial dos munícipios, a análise recai sobre um grupo de elementos que juntos possibilitam a formação de indicadores referentes a estrutura social e produtiva do território municipal, possibilitando identificar os seguintes elementos:

g. Dependência da população em idade produtiva em relação àqueles em idade de pouca atividade produtiva (taxa de dependência: pop. até 14 anos + pop. com 65 anos ou mais / pop. total X 100).

h. Dependência da população total em relação ao número de pessoas que são dependentes de repasse de Bolsa Família (BF) e do Instituto Nacional de Serviço Social (INSS) (taxa de dependência de pobres e aposentados: pop. dependente de BF + repasses do INSS / pop. total X 100).

i. Capacidade técnica e política do município em atrair investimentos públicos para solucionar problemas estruturais (percentual de crescimento dos investimentos externos dado pelo consumo de energia dos anos analisados e os repasses dos governos do Estado e Federal em obras, habitação e saneamento).

j. Capacidade de crescimento dos setores fundamentais da economia e do rendimento da população por meio do crescimento do Produto Interno Bruto (PIB) estratificado (agropecuária, industrial, comércio e serviços) e PIB per capita (soma do percentual de crescimento do PIB municipal + percentual de crescimento do PIB per capita / 2).

k. Investimentos destinados ao setor privado da economia, observando os valores destinados para a agropecuária + FCO (total) + valor contatado do Programa Nacional de Fortalecimento da Agricultura Familiar (PRONAF) (percentual de crescimento do financiamento da agricultura e da pecuária + investimento do $\mathrm{FCO}+$ investimentos do PRONAF / 3).

1. Crescimento do nível do emprego e participação de pessoas de nível superior no conjunto da População Economicamente Ativa (PEA), verificando o crescimento de empregos formais e visualizando o impacto do nível superior na PEA [variação percentual entre o emprego formal + (pessoas com ensino superior / pop. economicamente ativa X 100) / 2].

Dessa perspectiva, a classificação atribuída aos municípios tem como referência a média dos dados dos municípios do estado de Mato Grosso do Sul. Nesse sentido, é necessária a sistematização de todos os dados por município, com base nos indicadores de autogestão e de capacidade de sustentação territorial, para a obtenção da média do 
estado e a partir dessa média pontua-se 1 para a pior condição e 3 para a melhor condição.

Assim, quanto maior for o número pior a situação do município. Nesse caso, pontua-se na sua condição invertida, sendo que para pontuação superior a 2 o intervalo é de dois em dois e para pontuação inferior a 2 o intervalo é de um em um.

Portanto, a partir do cruzamento dos indicadores de capacidade de autogestão com os de capacidade de sustentação territorial, é possível classificar os municípios em três categorias: municípios estáveis - municípios que apresentam indicadores superiores a 2.0 na autogestão e na sustentação territorial; municípios inconstantes - municípios que apresentam indicador superior a 2.0 apenas na autogestão ou na sustentação territorial; e municípios instáveis - municípios que apresentam indicadores inferiores a 2.0 na autogestão e na sustentação territorial.

A utilização dos indicadores de autogestão e de sustentação da base territorial do município é importante, mas não suficiente para aferir a real condição dos municípios em sua centralidade territorial. Nesse sentido, Oliveira \& Martins Jr. (2016) também afirmam a importância de estudos mais aprofundados a respeito das articulações que cada município estabelece com os demais municípios do estado, com outros estados da federação e com o exterior.

Segundo os autores, a boa competitividade territorial é fundamental para uma boa competitividade individual dos municípios, o que dá mais relevância para as articulações como sustentação da inovação e do crescimento virtuoso. Para isso, existem três modalidades de circulação: fluxo de transações comerciais no âmbito regional (estadual), a comercialização (saída e entrada) de produtos para outros estados e o comércio export-import dos municípios com outros países.

Neste trabalho, a fonte dos dados foram as notas fiscais eletrônicas, que possibilitaram detectar o número de operações realizadas entre os municípios e o número de operações realizadas desses municípios com as demais unidades da federação e com outros países. Para o mercado internacional, foram utilizados dados sobre as importações e importações disponibilizados pelo Ministério do Desenvolvimento, Indústria e Comércio Exterior, por unidade da federação e por município, considerando a soma dos valores das operações com exportação e importação.

Da mesma forma que se utilizou a pontuação de 1 para pior situação e 3 para a melhor situação nos indicadores de autogestão e de sustentação territorial, o mesmo critério foi utilizado para o indicador de circulação internacional dos municípios.

Para a circulação internacional, a pontuação foi considerada a partir do valor base de U\$ 1 milhão/ano do município e da quantidade superior a 10 países, somente para aqueles que tiveram operações de export-import superior a U\$ 1 milhão/ano.

Para a circulação nacional, a pontuação considerada foi de 100 operações/ano realizadas por município e a quantidade superior a 10 estados, independente do valor 
transacionado, atribuindo 1 para a circulação com até 10 estados da Federação ou com mais de 10 estados e menos de 100 operações/ano.

Para a circulação estadual, considerou-se os números de 100, 500 e 1000 operações de compra e venda realizadas entre os municípios por ano, não avaliando, neste caso, as transações realizadas dentro do próprio município, atribuindo 1 para municípios com até 100 operações/ano e com menos de 10 outros municípios, até 3 para município que realizou 1001 ou mais operações/ano com 10 ou mais municípios.

Com base na metodologia proposta por Oliveira \& Martins Jr. (2016), soma-se a pontuação das circulações (estadual, nacional e internacional) e divide-se por três, o que possibilitará um número para cada município, permitindo qualificar a capacidade de articulação dos municípios em: a) Baixa: 1 a 1.66 pontos. B) Média: 1.67 a 2.33 pontos. C) Alta: Superior a 2.34 pontos.

Dessa forma e com base na capacidade de autogestão e de sustentação territorial, é possível classificar os municípios do estado em três situações:

1. Satisfatória - municípios com bom nível de estabilidade administrativa e territorial e com alta ou mediana capacidade de articulação.

2. Incômoda - municípios com estabilidade administrativa e territorial, mas com baixa capacidade de articulação, ou aqueles inconstantes, que possuem uma articulação mediana, ou ainda aqueles instáveis, mas que, por algum bom motivo, possuem uma alta capacidade de articulação.

3. Delicada - municípios inconstantes com baixa capacidade de articulação e/ou instáveis que não consolidam uma alta articulação.

\section{As regiões fronteiriças de Ponta Porã e Corumbá}

Segundo Oliveira (2005), as regiões de fronteira são verdadeiros subsistemas abertos, isto em função das várias formas de complementariedades existentes nessas regiões, o que dificulta, em muitos casos, o controle burocrático do Estado. Sob a atuação do Estado nessas regiões, o autor retrata ainda que as leis no Estado-Nação funcionam de forma horizontal, mas nas fronteiras têm-se duas legislações que se impõem ou se contrapõem, de forma horizontal e vertical.

Para compreender a fronteira, Oliveira (2005, p. 382) afirma que "devemos depreender as especificidades de seus fluxos e suas conexões íntimas com o território." É nesse sentido que a economia da fronteira busca, segundo Wrong-Gonzáles (2002), uma integração de forma funcional, ou seja, ela se origina das próprias forças do mercado e se organiza por meio das articulações dos agentes sociais; enquanto o Estado busca meios para uma integração formal regulada por acordos.

Sobre a funcionalidade e formalidade das regiões de fronteira, Oliveira (2005, p. 385-389) classifica quatro diferentes tipologias de relações fronteiriças. A primeira 
delas é a chamada fronteira morta (baixa integração formal e funcional). Esse tipo de fronteira não possui articulações entre si, não há relação de proximidade entre os países membros. Normalmente há ausência de infraestrutura rodoviária, o que dificulta a circulação de pessoas e mercadorias. A segunda é território perigoso (baixa integração formal com alta integração funcional): A principal característica desse tipo de região é a informalidade nas relações comerciais e sociais, com presença corriqueira de trabalho ilícito, são regiões que não costumam atrair grandes atividades comerciais. Nas transações comerciais predominam o uso de papel moeda ao invés de cartões de créditos.

A terceira tipologia constitui as fronteiras vivas (alta integração formal e funcional). Nessas regiões são comuns as trocas de produtos e informações, especialmente nas conturbações. Por fim, a quarta é a fronteira burocrática (alta integração formal com baixa integração funcional). Neste tipo de fronteira há predomínio de ações estatais ou empresariais como forma de potencializar sua posição competitiva no mercado.

Estudemos o caso do município de Ponta Porã. Criado em 1912, Ponta Porã possui população, segundo o Instituto Brasileiro de Geografia e Estatística (2010), de 89.592 habitantes e está localizado na linha de fronteira entre Brasil e o Paraguai. A cidade está conurbada com a cidade-gêmea de Pedro Juan Caballero - Paraguai que, segundo dados do governo do Paraguai (2012) conta com 108.625 habitantes.

Na zona rural, a economia do município de Ponta Porã está voltada à pecuária e à agricultura (soja, trigo e milho), já na área urbana, a principal fonte de renda é o comércio, a indústria e a prestação de serviços. Em função da facilidade de transição entre as duas cidades, o comércio da região se intensificou, atraindo turistas para compras no Brasil e no Paraguai.

Por ser conurbada com a cidade-gêmea Paraguai de Pedro Juan Caballero, Ponta Porã tornou-se foco do turismo de compras, aumentando a sua dinâmica populacional e de mercadorias com as demais cidades do estado e do Brasil. Cidadesgêmeas são "lugares onde as simetrias e assimetrias presentes entre sistemas territoriais nacionais são mais visíveis e que podem se tornar um dos alicerces da cooperação com os outros países da América do Sul e consolidação da cidadania." (MACHADO, et. al., 2005, p. 108).

Segundo o Regic (2007), Ponta Porã é classificada também como Centro de Zona A, característica que pode indicar que a cidade é um bom influenciador na região sudoeste do estado, em articulação com Dourados e Campo Grande, consideradas capitais regionais segundo o mesmo estudo.

O objetivo no estudo desses municípios foi estabelecer indicadores que permitiram posicioná-los conforme detalhamento apresentado no ítem "Proposição Metodológica", em que são apresentados os indicadores de capacidade de autogestão, sustentação territorial e de articulação com entes estaduais, nacionais e internacionais. 
O cálculo desses indicadores envolveu a evolução das receitas e despesas públicas dos municípios estudados e dados estatísticos de três anos (201-2015) como: receita tributária, receita corrente, fundo partidário, ICMS, despesas com: saúde, educação, assistência social, encargos com pessoal e bolsa família, despesas correntes, taxa de dependência de pobres e aposentados, crescimento dos investimentos em: obras, habitação, saneamento, agropecuária, FCO e PRONAF, crescimento do PIB e do emprego. Além desses indicadores, também foram tabuladas as notas ficais eletrônicas de todos os estabelecimentos dos municípios para detectar o número de operações realizadas e, assim, mapear o fluxo de transações comerciais. Pelo volume de dados coletados, não é possível detalhá-los aqui, os mesmos podem ser consultados nas fontes oficiais.

$\mathrm{O}$ indicador de autogestão possibilita a observação da capacidade que o município tem de se autogerir e, partindo dos dados apresentados, é possível ter a noção sobre o nível de estabilidade administrativa do município. O resultado do indicador de autogestão de Ponta Porã ficou em 2,50 de um total de 3 pontos possíveis, apresentando uma boa capacidade de gestão pública dos seus gastos. Dos 6 índices que compõem esse indicador, o único em que o município apresentou fragilidade foi referente a parcela dos investimentos nos orçamentos municipais.

Já o indicador de sustentação territorial configura uma relação de indicadores capazes de apresentar as dinâmicas sociais e de produção das cidades. Analisando essas informações obteve-se uma compreensão das condições do território, tanto na parte econômica, quanto populacional e social. $\mathrm{O}$ resultado do indicador de sustentação territorial de Ponta Porã foi de 2,17 pontos, alto em comparação a outras cidades do estado, sendo possível considerar as dinâmicas de investimentos do município como satisfatórias, indicando que Ponta Porã apresenta uma boa captação dos investimentos públicos e privados que podem ser revertidos para políticas socioeconômicas.

Dos 6 índices analisados para a composição desse indicador, os que demonstraram maior fragilidade foram: a baixa capacidade técnica e política do município em atrair investimentos públicos para solucionar problemas estruturais; e o baixo crescimento do nível do emprego, bem como a participação de pessoas de nível superior no conjunto da população economicamente ativa.

Segundo Oliveira \& Martins Jr. (2016), a articulação, tanto nas redes de comunicação como na circulação, aparece como importante elemento para criar vantagens adicionais na localização do município. Uma cidade bem articulada com outros entes governamentais pode acabar ganhando vantagens políticas, econômicas e até mesmo sociais como programas de incentivo a moradia, de crédito, entre outros.

Por isso a importância de se aferir o grau de articulação que Ponta Porã tem nos três níveis, que são: indicador regional, referente às demais cidades de Mato Grosso do Sul; indicador nacional, que faz menção a outros estados do Brasil; e indicador internacional, que envolve outros países. 
Nos três indicadores de articulações, Ponta Porã conseguiu a nota máxima de 3 pontos. Em relação aos demais estados do país, a cidade teve mais relações comerciais com São Paulo, Paraná, Santa Catarina e Rio Grande do Sul, com destaque para o estado do Paraná. Quanto as suas articulações internacionais, a maior articulação foi com o país vizinho Paraguai.

Com os números de articulações regionais, foi possível identificar as redes de influência de Ponta Porã com os demais municípios do estado de Mato Grosso do Sul, destacando que suas relações no estado também ganharam a nota máxima de 3 pontos. Ponta Porã apresentou um grande número de operações financeiras com sete munícipios do estado: Campo Grande, Dourados, Amambaí, Aral Moreira, Antônio João, Bela Vista e Laguna Caraapã, como pode ser observado na Figura 1.

Por sua posição fronteiriça, a economia de Ponta Porã se articula tanto com o território local e regional como com o mercado internacional, estabelecendo fluxo comercial ligado por redes que atuam nos circuitos espaciais de produção e/ou de circulação. Essas características interferem nas articulações horizontais do território e, consequentemente, na configuração de uma rede urbana local/regional.
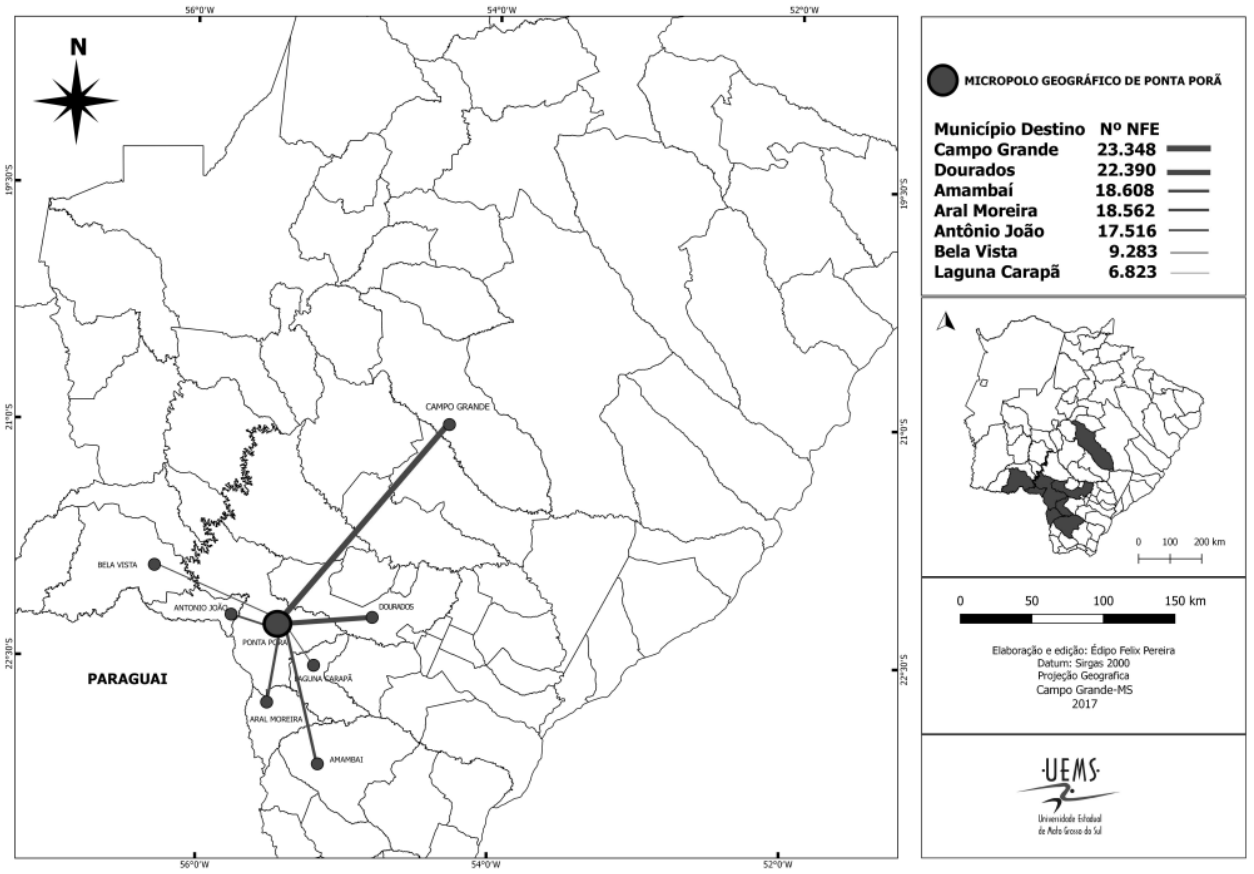

Figura 1: Rede de articulação do micropolo geográfico de Ponta Porã no estado de Mato Grosso do Sul (2013-2015) 
O município de Ponta Porã é um influenciador na região sudoeste do estado, tornando-se foco de políticas econômicas tanto privadas como públicas, fortalecendo a economia local e ajudando a sustentar o "título" de micropolo geográfico de ligação fronteiriço pelas suas dinâmicas de comércio, troca de serviços e sua relação fronteiriça com a cidade paraguaia de Pedro Juan Caballero.

Assim, por estar localizado em fronteira seca com o Paraguai, a cidade de Ponta Porã se destaca por suas articulações comerciais com o país vizinho. Segundo Oliveira (2016), os fluxos de cargas de Ponta Porã com outros países mais que dobram a cada três anos e os de viagens a cada quatro anos.

Classificada, segundo Oliveira (2005, p. 404), como uma fronteira viva (alta integração formal com alta integração funcional), "Pedro Juan Caballero e Ponta Porã formam uma conurbação vibrante, recheada de ações formais e complementariedades funcionais plurais", destacando-se com alto grau de articulação regional e sub-regional, tanto em nível comercial quanto na prestação de serviços.

Outra importante observação refere-se aos dados dos indicadores, pois ao somar os indicadores iniciais de autogestão e sustentação territorial, é possível afirmar que segundo a metodologia utilizada, o município de Ponta Porã apresenta uma boa capacidade de se autogerir com os recursos obtidos por meio de receitas próprias e de arrecadação, apresentando grande crescimento no comércio, com investimentos e crescimento do PIB municipal.

Vejamos o caso do município de Corumbá. Criado em 1850, Corumbá possui população de 103.703 habitantes (IBGE, 2010) e está localizado na linha de fronteira entre Brasil e a Bolívia. Como referido anteriormente, o objetivo no estudo desses municípios foi estabelecer indicadores que permitiram posicioná-los em relação à capacidade de autogestão e sustentação territorial, bem como, de articulação com entes estaduais, nacionais e internacionais.

O indicador de autogestão possibilita a observação da capacidade de autogestão do município, nessa classificação, o município de Corumbá ficou em 2,00 pontos de um total de 3 pontos possíveis, apresentando limite no grau de estabilidade da capacidade de gestão pública de seus gastos. Dos 6 itens analisados, os que apresentaram maior fragilidade foram: dependência do município em relação ao repasse do ICMS; e o grau de interferência dos gastos sociais em relação às receitas.

No indicador de sustentação territorial, Corumbá apresentou um valor de 2,17 pontos, alto em comparação a outras cidades do estado, indicando que o município apresenta uma boa captação de investimentos públicos e privados. Dos 6 índices analisados para a composição desse indicador, os que demonstraram maior fragilidade foram: baixa capacidade técnica e política do município em atrair investimentos públicos para solucionar problemas estruturais; e baixo crescimento do nível do emprego, bem como a participação de pessoas de nível superior no conjunto da população economicamente ativa. 
Nos três níveis de articulações (regional, nacional e internacional), Corumbá conseguiu a nota máxima de 3 pontos para as articulações nacional e internacional, 1,2 para a articulação regional e 2,40 no indicador de articulação. As maiores transações comerciais dentro do País foram com os estados de São Paulo, Paraná, Minas Gerais e Rio Grande do Sul, com destaque para o estado de São Paulo.

A participação no mercado regional, nacional e internacional dos municípios do Mato Grosso do Sul são partes que interferem, de maneira ampla, na divisão territorial do trabalho, sendo impossível não considerar a circulação das cidades como alicerces das formas e dinâmicas da gestão administrativa e da sustentação territorial. (OLIVEIRA; MARTINS JR., 2016).

Em relação às articulações regionais, Corumbá possui maior articulação com as seguintes cidades: Ladário, Campo Grande, Aquidauana, Ribas do Rio Pardo, Dourados, Anastácio e Ponta Porã, conforme Figura 2.

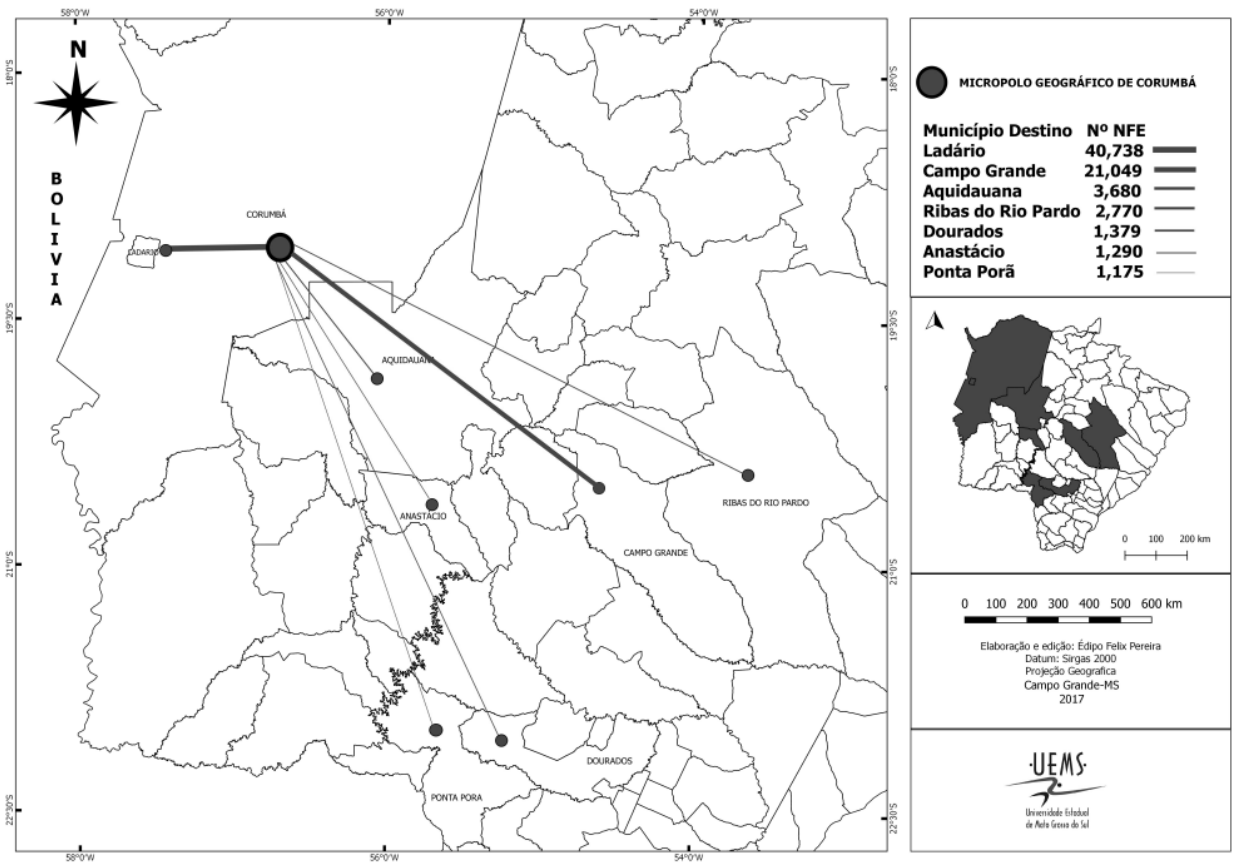

Figura 2. Rede de articulação do micropolo geográfico de Corumbá no estado de Mato Grosso do Sul (2013-2015)

\section{Considerações Finais}

Identificar a rede de articulação regional e nacional que o município estabelece, assim como sua capacidade de autogestão e sustentação territorial, é fundamental para 
proposições de mecanismos que aumentem a eficiência econômica dos centros urbanos, por meio do uso de estratégias e vantagens comparativas que possam beneficiar esses centros em função das articulações geográficas que as cidades fronteiriças estabelecem com os demais centros urbanos.

O uso dessa metodologia possibilitou, ainda, identificar a rede de ligação territorial e as áreas de influência das cidades fronteiriças, revelando a importância das pequenas e médias cidades na geografia urbana regional. Essas cidades possuem peculiaridades e articulações de complementariedade territorial nem sempre perceptível pelos órgãos oficiais, que se limitam, muitas vezes, à compreensão da dinâmica regional por meio da hierarquia das cidades, que não capta o real nível e a intensidade do fluxo de pessoas, serviços e capital em nível local.

Esses municípios fronteiriços estão ganhando atenção nos estudos e debates tanto econômicos quanto sociais, gerando uma maior compreensão de suas especificidades nas dinâmicas espaciais, tendo em vista que possuem diversidades culturais que exigem uma leitura meticulosa para a compreensão dessas relações, fazendo com que as regiões de fronteira mereçam contínuos estudos. Por estarem localizadas em fronteira seca com outros países, Ponta Porã e Corumbá se destacam também pela mobilidade de pessoas e capitais conectados aos fluxos locais e globais.

\section{Referências}

ALLEN, J.; MASSEY, D.; COCHRANE, A. Rethinking the Region. Londres: Routledge, 1998.

ARRAIAS, T. A. A cidade e a região/a cidade-região: reconhecer processos, construir políticas. Cadernos Metrópoles, São Paulo, n. 20, 2008.

BRADFORD, M. G.; KENT, W. A. Human Geography: Theories and their application. Oxford, 1977.

CORRÊA, R. L. Região e organização espacial. 8. ed. São Paulo: Ática, 2007.

FIRJAN. Índice Firjan de Desenvolvimento Municipal. Disponível em: http://www.firjan.com.br/ifdm/. Acesso em: 29 de set. 2016.

GARCIA, R. A.; LESMO, M. B. As áreas de influência dos pólos econômicos brasileiros: uma comparação entre dois modelos de regionalização. Anais do XV Encontro Nacional de Estudos Populacionais. Caxambú, 2006. Acesso em: http://www.abep.org.br/publicacoes/index.php/anais/article/view/1592/1555. Acesso em: 25 ago. 2017.

GETIS, A.; GETIS, J. Christaller's Central Place Theory. UFRÁSIO, M. A. (trad.) The Jornal of Geography, London, v. 65, n. 5, 1996. Disponível em:

https://www.tandfonline.com/doi/abs/10.1080/00221346608982415. Acesso em: 25 ago. 2017. 
GOMES, P. C. C. O conceito de região e sua discussão. In: CASTRO, I. E.; GOMES, P. C. C.; CORRÊA, R. L. Geografia: conceitos e temas. Rio de Janeiro: Bertrand Brasil, 2001. p. 59-60.

HAESBAERT, R. Regional - global: dilemas da região e da regionalização na geografía contemporânea. 2. ed. Rio de Janeiro: Bertrand, 2014.

INSTITUTO BRASILEIRO DE GEOGRAFIA E ESTATÍSTICA. IBGE Cidades: Informações sobre os municípios brasileiros. 2010. Disponível em:

http://www.cidades.ibge.gov.br/xtras/home.php. Acesso em: 27 de mar. 2017.

INSTITUTO BRASILEIRO DE GEOGRAFIA E ESTATÍSTICA. Regiões de Influência das Cidades. Rio de Janeiro, 2008.

LENCIONI, S. Urbanização difusa e a constituição de megarregiões: O caso de São Paulo-Rio de Janeiro. Revista Eletrônica e-Metropolis, Rio de Janeiro, n. 22, p. 6-15, 2015. Disponível em: http://emetropolis.net/artigo/167?name=urbanizacao-difusa-e-aconstituicao-de-megarregioes-o-caso-de-sao-paulo-rio-de-janeiro. Acesso em: 11 set. 2017.

LENCIONI, S. Região e Geografia. São Paulo: Edusp, 2004.

MACHADO, L. O.; et. al. O desenvolvimento da faixa de fronteira: uma proposta conceitual-metodológica. In: OLIVEIRA, T. C. M. Território sem limites: estudos sobre fronteiras. Campo Grande: UFMS, 2005. p. 87-112.

OLIVEIRA, T. C. M.; MARTINS Jr., C. Estabilidade e articulação dos municípios do Mato Grosso do Sul: proposições para uma sugestão metodológica. In: LAMOSO, L. P. (Org.). Temas do desenvolvimento econômico brasileiro e suas articulações com o Mato Grosso do Sul. Curitiba: Íthala, 2016. p. 233-264.

OLIVEIRA, T. C. M. Tipologia das relações fronteiriças: elementos para o debate teórico-prático. In: OLIVEIRA, T. C. M. Território sem limites: estudos sobre fronteiras. Campo Grande: UFMS, 2005. p. 377-408.

OLIVEIRA, T. C. M. Polos Geográficos de Ligação - Um estudo sobre a rede de cidades na geografia econômica do Mato Grosso do Sul e suas conurbações de fronteira. Relatório Técnico de Projeto de Pesquisa. Programa de Desenvolvimento Científico e Tecnológico Regional FUNDECT/CNPq. Campo Grande: 2016.

PARAGUAY. Proyección distrital. Proyección de la población por sexo y edad, según distrito, 2000-2025. Dirección General de Estadística, Encuestas y Censos, 2015.

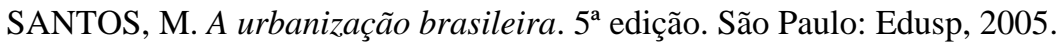

SANTOS, M. Espaço e método. 5. ed. São Paulo: Edusp, 2008.

SANTOS, Milton; SILVEIRA, Maria Laura. O Brasil: território e sociedade no início do século XXI. 9. ed. Rio de Janeiro: Record, 2006. 
SCOTT, A.; et. al. Cidades-regiões globais. Espaço \& Debates, São Paulo, n. 41, p.1125. 2001.

WRONG-GONZALES, P. Alianzas estratégicas de regiones transfronteirizas: cooperacion y conflito em la frontera USA-Mexico. In: MASE, F.; BORDA, D. Economías regionales y desarrollo territorial. CADEP: Assunción, 2002. p. 149-179.

* Esse trabalho é resultado da pesquisa de pós-doutorado desenvolvida no Programa de Mestrado em Estudos Fronteiriços, do Campus do Pantanal da Universidade Federal de Mato Grosso do Sul, sob a supervisão do Prof. Dr. Antonio Firmino de Oliveira Neto, e orientação do Prof. Dr. Tito Carlos Machado de Oliveira.

\author{
Walter Guedes da Silva \\ Doutor em Geografia Humana pela Universidade de São Paulo, Mestre em \\ Desenvolvimento Sustentável pela Universidade de Brasília e Geógrafo pela \\ Universidade Federal da Grande Dourados. Atualmente é professor efetivo dos \\ cursos de Geografia, licenciatura e bacharelado, e do Programa de Pós-graduação \\ Stricto Sensu - Mestrado Profissional em Educação da Universidade Estadual de \\ Mato Grosso do Sul. \\ Rua 14 de julho, 4465, torre 1, ap. 1605, Garden das Palmeiras, bairro São Francisco, \\ CEP: 79.010-470. Campo Grande (MS). \\ E-mail: guedes@uems.br
}

Recebido para publicação em abril de 2018 Aprovado para publicação em julho de 2018 